\title{
EDUCAÇÃO E(M) DIREITOS HUMANOS E BNCC: competências socioemocionais e ética ambiental
}

\author{
HUMAN RIGHTS EDUCATION AND BNCC: Socioemotional competences and environmental \\ ethics
}

\author{
Daniela Rosendo ${ }^{1}$ \\ Fernanda Brandão Lapa²
}

\begin{abstract}
Resumo: O objetivo do artigo é compreender a relação entre a ética ambiental e as competências socioemocionais previstas na Base Nacional Comum Curricular (BNCC), alinhadas com a Educação em Direitos Humanos (EDH), a Educação para a Cidadania Global (ECG) e a Educação Ambiental. Assim, são apresentados os conceitos de EDH e ECG, situados nos marcos legais que as estabelecem, e como elas dialogam com o desenvolvimento de habilidades socioemocionais visadas pela educação do século XXI, isto é, que vai além das competências cognitivas. Alinhada com esse marco teórico e legal, a BNCC apresenta um conjunto de competências gerais que visam justamente 0 desenvolvimento dessas habilidades, incluindo os elementos e valores dos direitos humanos e da sustentabilidade ambiental. Contudo, é preciso estabelecer os valores morais e éticos que devem orientar essa educação, de modo que rompa com o antropocentrismo e não incorra em nenhuma forma de opressão, seja em relação aos humanos, aos animais ou à natureza.
\end{abstract}

Palavras-chave: Educação ambiental. BNCC. Direitos humanos. Competências socioemocionais. Educação em Direitos Humanos.
Abstract: The article aims to understand the relationship between environmental ethics and socioemotional competences foreseen in the National Common Curricular Basis (BNCC), aligned with Human Rights Education (EDH), Global Citizenship Education (ECG) and Environmental Education. Thus, the concepts of EDH and ECG are presented, situated in the legal frameworks that establish them and how they dialogue with the development of socialemotional skills aimed at education in the 21st century, that is, that goes beyond cognitive competences. In line with this theoretical and legal framework, the BNCC presents a set of general competencies that aim precisely at the development of these skills, including the elements and values of human rights and environmental sustainability. However, it is necessary to establish the moral and ethical values that should guide this education, so that it breaks with anthropocentrism and does not incur any form of oppression, either in relation to humans, animals or nature.

Key-words: Environmental education. NBCC. Human Rigths. Socioemotional competences. Human Rights Education.

\section{INTRODUÇÃO}

O direito à educação não deve ser restrito ao acesso de todas e todos, mas deve abranger também uma educação que promova o desenvolvimento humano. Portanto, deve garantir conhecimento, mas também ferramentas e instrumentos para o uso ético, responsável e sustentável do conhecimento, ou seja, de uma educação para a cidadania que abrange habilidades cognitivas e não cognitivas, nelas incluídas as habilidades sociais como empatia, resolução de conflitos e interação sociocultural e ambiental, por exemplo.

Essa educação - seja no âmbito formal ou não formal - visa formar cidadãs e cidadãos que assumam papeis ativos na construção de uma sociedade mais igualitária, justa, pacífica e sustentável.

\footnotetext{
${ }^{1}$ Doutoranda e Mestra em Filosofia pela Universidade Federal de Santa Catarina(UFSC). E-mail: <daniela.rosendo84@gmail.com>

2 Professora de Direitos Humanos e Coordenadora da Clínica de Direitos Humanos da Universidade da Região de Joinville (UNIVILLE). E-mail: <flapa@iddh.org.br>
} 
A Base Nacional Comum Curricular (BNCC), que visa estabelecer conhecimentos, competências e habilidades que devem ser desenvolvidas por todos/as os/as estudantes durante o ensino básico, resguardando as especificidades regionais, estabelece competências gerais e específicas para as diferentes áreas de conhecimento e respectivos componentes curriculares.

As competências gerais abrangem as chamadas competências socioemocionais, que dialogam com os princípios da Educação em Direitos Humanos (EDH) previstas no Plano Nacional de Educação em Direitos Humanos (PNEDH), que dentre seus objetivos gerais enfatiza "o papel dos direitos humanos na construção de uma sociedade justa, equitativa e democrática” (BRASIL, 2007, p. 26).

A BNCC prevê também a inclusão da educação ambiental, que deve ser um meio para a preservação do meio ambiente, que deve ser "ecologicamente equilibrado" para as presentes e futuras gerações, conforme a principiologia constitucional.

Nesse sentido, é importante compreender como as competências socioemocionais cumprem um papel fundamental no desenvolvimento de uma consciência ambiental. Contudo, resta ainda o desafio de compreender como eticamente deve ser orientada essa perspectiva de sustentabilidade.

\section{EDUCAR EM DIREITOS HUMANOS (EDH): Educar para uma cidadania global (ECG)}

Em 1995, a ONU estabeleceu a Resolução 49/184, que instituiu a Década das Nações Unidas para a Educação em Matéria de Direitos Humanos e definiu Educação em Direitos Humanos (EDH) como:

[...] os esforços de formação, divulgação e informação destinados a construir uma cultura universal de direitos humanos através da transmissão de conhecimentos e competências e da modelação de atitudes, com vista a:

a) Reforçar o respeito pelos direitos humanos e liberdades fundamentais;

(b) Desenvolver em pleno a personalidade humana e o sentido da sua dignidade;

(c) Promover a compreensão, a tolerância, a igualdade entre os sexos e a amizade entre todas as nações, povos indígenas e grupos raciais, nacionais, étnicos, religiosos e linguísticos;

(d) Possibilitar a participação efetiva de todas as pessoas numa sociedade livre;

(e) Promover as atividades das Nações Unidas em prol da manutenção da paz.

(ONU, 1994, p. 11-12) (grifo nosso)

Percebe-se aqui que o desenvolvimento da plena personalidade humana somente é possível em um ambiente que valoriza as diversidades existentes nas diferentes sociedades, sejam elas culturais, sociais, econômicas ou religiosas.

A EDH também é assegurada pela Declaração das Nações Unidas sobre Educação e Formação em Matéria de Direitos Humanos, de 2011, considerada essencial para a garantia de demais direitos humanos:

\section{Artigo 1}

1. Toda pessoa tem direito de possuir, procurar e receber informações sobre todos os direitos humanos e liberdades fundamentais e deve ter acesso à educação e formação em direitos humanos.

2. A educação e formação em matéria de direitos humanos são essenciais para a promoção do respeito universal e eficaz de todos os direitos humanos e as liberdades fundamentais de todas as pessoas, de acordo com os princípios da universalidade, indivisibilidade e interdependência dos direitos humanos. [...]

Artigo 2

1. Educação e a formação em matéria de direitos humanos estão integradas pelo conjunto de atividades educativas e de formação, informação, sensibilização e aprendizagem que têm por objetivo promover o respeito universal e eficaz de todos os direitos humanos e liberdades fundamentais, contribuindo assim, entre outras coisas, para a prevenção de abusos e violações de direitos humanos ao proporcionar às pessoas conhecimentos, habilidades e compreensão e 
desenvolver suas atitudes e comportamentos para que possam contribuir para a criação e promoção de uma cultura universal de direitos humanos. [...] (ONU, 2011, p. 2-3)

A educação e formação em direitos humanos incluem: a educação sobre os direitos humanos, a educação por meio dos direitos humanos e a educação para os direitos humanos.

A Declaração enfatiza que a EDH é um processo para toda a vida, todas as idades, todos os setores da sociedade, todos os níveis e formas de educação (art. $3^{\circ}$ ) e deve ser baseada nos princípios da igualdade, especialmente entre meninas e meninos, homens e mulheres, na dignidade humana, na inclusão e na não discriminação (art. $\left.5^{\circ}, 1\right)$.

Faz-se mister, então, que esta EDH esteja presente em todos os momentos e ambientes políticos, sociais e educativos encontrados ao alcance das/os participantes deste processo e que seja também contextualizada à vida dessas pessoas para fazer sentido (LAPA, 2014). De maneira semelhante, no Brasil, o PNEDH, conceitua a EDH como:

[...] um processo sistemático e multidimensional que orienta a formação do sujeito de direitos, articulando as seguintes dimensões:

a) apreensão de conhecimentos historicamente construídos sobre direitos humanos e a sua relação com os contextos internacional, nacional e local;

b) afirmação de valores, atitudes e práticas sociais que expressem a cultura dos direitos humanos em todos os espaços da sociedade;

c) formação de uma consciência cidadã capaz de se fazer presente em níveis cognitivo, social, ético e político;

d) desenvolvimento de processos metodológicos participativos e de construção coletiva, utilizando linguagens e materiais didáticos contextualizados;

e) fortalecimento de práticas individuais e sociais que gerem ações e instrumentos em favor da promoção, da proteção e da defesa dos direitos humanos, bem como da reparação das violações. (BRASIL, 2007, p. 25)

Nesse mesmo sentido, as Diretrizes Nacionais para a Educação em Direitos Humanos, aprovadas em 2012, afirmam que:

A EDH deve ser orientada para o respeito às diferenças e ao compromisso com a transformação da realidade. Deve sensibilizar o indivíduo a participar de um processo ativo na resolução dos problemas em um contexto de realidades específicas e orientar a iniciativa, o sentido de responsabilidade e o empenho de edificar um amanhã melhor. (BRASIL, 2013, p. 35) (grifo nosso)

Fernando Reimers (2009b), Professor da Universidade de Educação em Harvard, explicita a importância da EDH no século XXI ao afirmar que os direitos humanos nos orientam moralmente, propiciando inclusive a negociar as diferenças. Nesse sentido, compreender os direitos humanos por meio da EDH passa a ser uma competência global. Propiciar que os/as alunos/as desenvolvam essa competência é fundamental para os desafios também globais que precisam ser enfrentados.

O desenvolvimento de valores globais (a primeira, ética, dimensão da competência global) pode ser alcançado com base na base de conhecimentos bem estabelecida na educação em direitos humanos, ensinando estudantes não apenas ao conhecimento dos direitos e à sua história, mas para apreciar e valorizar estes direitos, discernir como eles são mantidos nas várias comunidades das quais os alunos fazem parte e atuar em direção ao trabalho em andamento, que é a conquista desses direitos. Ensinar a compreender a importância dos direitos humanos e agir de acordo com esse entendimento é a pedra angular da civilização global e da paz [...]. (REIMERS, 2009a, p. 191). 
Semelhante aos estudos sobre competências no âmbito global, mencionada por Reimers, tem-se também o conceito de Educação para a Cidadania Global (ECG), desenvolvido pela UNESCO, a Agência especializada da ONU para a Educação, Ciência e Cultura, a partir de 2015. Para a UNESCO (2015a, p. 2), "cidadãos globais são indivíduos que pensam e agem para um mundo mais justo, pacífico e sustentável" (grifo nosso).

Desse modo, a ECG visa:

[...] equipar alunos de todas as idades com valores, conhecimentos e habilidades que sejam baseados e promovam o respeito aos direitos humanos, à justiça social, à diversidade, à igualdade de gênero e à sustentabilidade ambiental. Além de empoderar os alunos para que sejam cidadãos globais responsáveis, a ECG oferece as competências e as oportunidades de concretizar seus direitos e suas obrigações, com vistas a promover um mundo e um futuro melhores para todos. (UNESCO, 2015a, p. 2) (grifo nosso)

A denominação ECG surge para unir conceitos, metodologias e teorias de diferentes campos, como a educação em direitos humanos, educação para a paz, educação para o desenvolvimento sustentável etc. Busca "avançar suas agendas superpostas, que compartilham um objetivo comum de fomentar um mundo mais justo, pacífico e sustentável" (UNESCO, 2015b, p. 9) e deve ser encarada "como uma disciplina transdisciplinar e não como uma matéria separada ou superposta" (UNESCO, 2015b, p. 15).

Essa visão baseia-se nos 4 (quatro) pilares da educação, desenvolvidos pela Comissão Internacional sobre a Educação para o Século XXI, em 1996: Aprender a conhecer; aprender a fazer; aprender a ser e aprender a conviver (DELORS, 2010).

A ECG tem o intuito de fomentar 3 (três) dimensões conceituais chave nos/nas educandos/as:

Habilidades cognitivas (hard skills): Os alunos adquirem conhecimentos, compreensão e raciocínio crítico sobre questões globais e sobre a interconectividade/ interdependência entre países e entre diferentes populações

\section{Habilidades socioemocionais (soft skills): Os alunos têm o sentimento de pertencer a uma humanidade comum, ao compartilhar valores e responsabilidades e possuir direitos. Os alunos demonstram empatia, solidariedade e respeito por diferenças e diversidade}

Habilidades comportamentais: Os alunos agem de forma efetiva e responsável nos contextos local, nacional e global, em prol de um mundo mais pacífico e sustentável. (UNESCO, 2015a, p. 3) (grifo nosso)

Esse pertencimento a uma humanidade comum também incorpora a ideia de um pertencimento a um mesmo planeta e a um mesmo espaço ambiental. Conforme o Conselho Nacional de Educação, na Resolução $\mathrm{CNE} / \mathrm{CP} \mathrm{n}^{\circ}$ 1/2012, a educação em direitos fundamenta-se também no princípio da sustentabilidade socioambiental. Segundo Lapa e Rodrigues:

A EDH deve estimular o respeito ao espaço público como bem coletivo e de utilização democrática de todos/as. Nesse sentido, colabora para o entendimento de que a convivência na esfera pública se constitui numa forma de educação para a cidadania, estendendo a dimensão política da educação ao cuidado com o meio ambiente local, regional e global. A EDH, então, deve estar comprometida com o incentivo e promoção de um desenvolvimento sustentável que preserve a diversidade da vida e das culturas, condição para a sobrevivência da humanidade de hoje e das futuras gerações. (LAPA; RODRIGUES, 2016, p. 191-192) (grifo nosso)

As habilidades socioemocionais/soft skills, que incorporam tanto um pertencimento à humanidade e meio ambiente comuns, são também abordadas na BNCC, que passa a estabelecer competências gerais 
a serem observadas por toda a educação básica no Brasil. Sendo assim, considerando sua importância, será tratada na sequência.

\section{BASE NACIONAL COMUM CURRICULAR E COMPETÊNCIAS SOCIOEMOCIONAIS}

\section{A construção da $\mathrm{BNCC}^{3}$}

No Brasil existem inúmeros documentos normativos que se relacionam diretamente com o tema da educação. A BNCC é mais um documento que vem com o mesmo propósito, qual seja nortear e apresentar parâmetros gerais para a educação brasileira, em especial a educação básica.

Importa destacar que, no tocante à educação escolar, ao redigir o art. 210 da Constituição Federal, o Constituinte Originário previu que fossem "fixados conteúdos mínimos para o ensino fundamental, de maneira a assegurar formação básica comum e respeito aos valores culturais e artísticos, nacionais e regionais" (BRASIL, 1988). Por este motivo, foi elaborada a Lei de Diretrizes e Bases da Educação (LDB).

Da mesma forma, na redação dada pelo Constituinte, o art. 214 previu a implantação do Plano Nacional de Educação (PNE), cuja redação foi alterada pela Emenda Constitucional $n^{\circ}$ 59/2009, que estabeleceu a duração como decenal (originalmente plurianual) e especificou seu objetivo:
Art. 214. A lei estabelecerá o plano nacional de educação, de duração decenal, com o objetivo de articular o sistema nacional de educação em regime de colaboração e definir diretrizes, objetivos, metas e estratégias de implementação para assegurar a manutenção e desenvolvimento do ensino em seus diversos níveis, etapas e modalidades por meio de ações integradas dos poderes públicos das diferentes esferas federativas que conduzam a:
I - erradicação do analfabetismo;
II - universalização do atendimento escolar;
III - melhoria da qualidade do ensino;
IV - formação para o trabalho;
V - promoção humanística, científica e tecnológica do País.
VI - estabelecimento de meta de aplicação de recursos públicos em educação como proporção do produto interno bruto. (grifo nosso)

Sendo assim, em 2014 foi sancionada a Lei n 13.005, que aprovou o Plano Nacional de Educação (PNE). Dentre as várias estratégias por ele definidas, destaca-se a "implantação dos direitos e objetivos de aprendizagem e desenvolvimento que configurarão a base nacional comum curricular do ensino fundamental" (BRASIL, 2014).

Estabeleceu-se o Ministério da Educação (MEC) como o responsável por coordenar a redação da BNCC, a qual teve sua versão final homologada pelo então Ministro da Educação, Mendonça Filho, em 20 de dezembro de 2017. Segundo estabeleceu o PNE, a BNCC deveria ser elaborada e apresentada para aprovação ao Conselho Nacional da Educação (CNE) em até 2 (dois) anos. Em 2014 foi iniciada a elaboração da $1^{\text {a }}$ versão, a qual foi divulgada e teve consulta pública, em setembro de 2015.

A $2^{\mathrm{a}}$ versão foi divulgada em maio de 2016, e em seguida foram realizados Seminários Estaduais, de

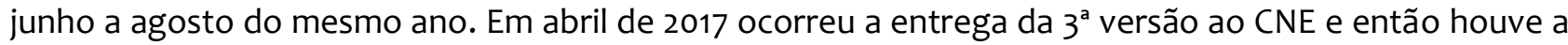
realização de Audiências Públicas Regionais, de julho a novembro, para então chegar à homologação final em dezembro de 2017. A partir de 2018, é iniciado o Programa de Apoio à Implementação da BNCC, o qual implicará na (re)elaboração de currículos e materiais didáticos, formação de professores/as etc.

\section{Críticas ao processo de construção da BNCC}

\footnotetext{
3 Gostaríamos, nesta parte, de fazer um agradecimento especial à pesquisadora Suiany Zimermann Bail que, como assistente de uma consultoria sobre o tema da BNCC, levantou dados e informações aqui expostas.
} 
No texto "Uma base em falso", de autoria de Salomão Ximenes e Fernando Cássio, publicado online pelo Nexo Jornal, os autores enumeram algumas críticas contundentes à BNCC e ao seu processo de elaboração. Inicialmente, criticam a opção pela eliminação do Ensino Médio dessa versão da BNCC:

[...] a contradição de se lançar uma BNCC parcial, que não responde sequer à educação básica, ao excluir o ensino médio, quando a nova lei (n. 13.415, de 2017) que regula essa etapa caminha rumo à fragmentação da oferta em "itinerários formativos" de viés francamente classista, que limitam os conteúdos comuns aos destinatários da educação profissional. (XIMENES; CÁSSIO, 2017)

Para eles, essa escolha representa uma fragmentação de conteúdos totalmente contrária ao direito à educação escolar tal qual trazido pela Constituição Federal e assegurado pela LDB.

Em segundo lugar, a expressão "Direitos de Aprendizagem", como apresentada na Base, retira o enfoque da educação enquanto responsabilidade do Estado e o transfere aos professores/as. Por esse e outros motivos, consideram a BNCC um verdadeiro retrocesso para a educação, ainda mais se comparada ao PNE.

Longe de ser um mero neologismo, os chamados "direitos de aprendizagem" direcionam o enfoque das políticas educacionais para dentro da escola, mais especificamente para o trabalho dos professores. Estes passam a ser, em substituição ao dever do Estado, os responsáveis primazes pelo fracasso dos alunos, comprovado e repisado em sucessivas divulgações de avaliações externas. (XIMENES, 2017)

Terceiro, segundo eles, houve uma mudança considerável da $2^{\mathrm{a}}$ para a $3^{\mathrm{a}}$ - e aprovada - versão da BNCC. Alegam que ela se propunha elemento articulador do Sistema Nacional de Educação, tal qual previu o PNE, mas que passou a ser um elemento regulador das atividades da educação.

Em quarto lugar, salientam o enfoque em Competências na Base, o que traz à tona o Projeto dos Parâmetros Curriculares Nacionais (PCN), da década de 1990. Destaca-se que os ditos PCN sofreram duras críticas por valorizar competências e habilidades vantajosas ao mundo do trabalho, de viés neoliberal ou neoliberalizante, pela falta de participação dos/as professores/as, bem como por não terem sido considerados os demais documentos legais sobre educação (NUNES, pp. 95-96).

O último aspecto criticado foi justamente a participação social no processo de elaboração da Base. Segundo os autores, há uma tentativa por parte dos atores envolvidos no desenvolvimento e implantação da BNCC em convencer a sociedade que o processo de elaboração foi democrático e que as mudanças no governo federal em nada alteraram os rumos da educação formal brasileira.

Entretanto, afirmam os referidos autores que não existiram os alegados "amplos debates", mas apenas discussões acerca dos conteúdos e objetivos de ensino-aprendizagem. Dessa forma, acreditam que não houve participação pública, ao menos não suficiente, para a escolha dos temas centras do documento. Ainda, alegam que houve grande participação de movimentos empresariais, os quais, sob a forma de instituições que atuam em prol da Base, fizeram valer seus interesses privados nesse documento público.

Mas críticas não param por aí. Autores como Zacarias Gama reafirmam o caráter neoliberal das Competências definidas pela BNCC, e destacam que sua finalidade, mais do que garantir direitos de aprendizagem dos/as alunos/as, é formá-los/las com competências que lhes atribuam um perfil adequado ao mundo do trabalho.

As competências adquiridas e desenvolvidas são, portanto, determinantes de um perfil de alunos ao fim da escolaridade de níveis infantil e fundamental e, ao mesmo tempo, apontam para o tipo de cidadão e sociedade que se pretende coletivamente construir. São elas que permitirão aos alunos se apropriarem dos conhecimentos construídos historicamente, desfrutarem as manifestações artísticas e culturais, promoverem o entendimento mútuo, entenderem as relações sociais de produção, o exercício da cidadania e os seus próprios projetos 
de vida. Por um lado, constituem-se como expectativas de aprendizagem; mas que, por outro, são direitos de aprendizagem que precisam ser garantidos a todos os alunos. (GAMA, 2016)

Prossegue o mesmo autor ao alertar que à mera leitura da BNCC, o/a leitor/a pode não identificar interdições ou limitações ao potencial dos/as educandos/as, mas que isso fica claro se compararmos o documento brasileiro aos documentos internacionais, em especial relativos ao direito humano à educação (GAMA, 2016).

Especificamente sobre o critério hierárquico, a BNCC deve ser pautada de acordo com a norma fundamental (Constituição) e, em consonância com ela, devem ser interpretados os demais atos normativos.

Sendo assim, basta que sejam analisados em conjunto e em correto grau hierárquico, a ser considerado primeiro a Constituição Federal e os Tratados Internacionais de Direitos Humanos sobre o tema. Em seguida, por tratar-se de educação básica, a LDB, pois é a LC que visa complementar a Constituição. Na sequência, as leis que versam sobre a educação, como o PNE, Diretrizes Nacionais da Educação, o PNEDH etc. E então a BNCC, hierarquicamente inferior a todas as normas mencionadas. Dessa forma, a BNCC não pode ser lida, interpretada e implementada sem que haja a consideração de que no ordenamento jurídico brasileiro existem normas de superior hierarquia, as quais devem ser observadas em detrimento da Base.

Feita essa reflexão acerca do universo que permeia a elaboração e a homologação da BNCC, bem como observados os critérios de hierarquia normativa que devem ser observados para a sua correta implementação, cabe identificar, no texto tal qual se encontra, os caminhos possíveis para a aplicação da Educação em Direitos Humanos, componente essencial do direito à educação.

\section{As Competências socioemocionais}

Educar crianças para o século XXI, criar cidadãs/ãos globais e responsáveis pelo planeta em que vivem, buscar o pleno desenvolvimento humano são desafios que exigem ações de todos os atores envolvidos no processo da educação. Há tempo são utilizados testes que buscam mensurar a inteligência das/os educandas/os por intermédio da avaliação de suas competências cognitivas (habilidade de ler, de fazer contas etc.).

Entretanto, somente nas últimas décadas que pesquisadoras/es de diversas áreas do conhecimento têm trazido à tona a importância do desenvolvimento de competências que não são cognitivas, mas socioemocionais (ex: persistência, responsabilidade, curiosidade, empatia, cooperação etc.), para o pleno desenvolvimento da pessoa.

O processo de aprendizado que inclui as competências socioemocionais, também conhecidas como social and emotional skills ou soft skills, é também denominado Social and Emotional Learning (SEL).

O aprendizado social e emocional (SEL) é o processo através do qual as crianças e os adultos adquirem e aplicam efetivamente o conhecimento, as atitudes e as habilidades necessárias para entender e gerenciar as emoções, definir e atingir metas positivas, sentir e mostrar empatia para os outros, estabelecer e manter positivo relacionamentos e tomar decisões responsáveis. (SALZBURG GLOBAL SEMINAR, 2016, p. 8)

De acordo com Tonia Casarin (2016), Mestra pela Universidade de Columbia, Lemann Fellow e especialista em habilidades socioemocionais, o SEL divide-se em inteligências emocionais (voltadas às emoções, como nomeá-las e como lidar com elas) e sociais (referentes à empatia, à diversidade, ao olhar o outro, à convivência em sociedade, à cooperação).

Pesquisas demonstram que o SEL contribui para uma melhor autoestima, saúde mental e gerenciamento do estresse, e ajuda a desenvolver maior perseverança e resiliência. No mundo atual de competição, bullying e testes de alto risco na 
sala de aula e de turbulências econômicas e políticas fora dele, ser capaz de resistir aos choques e estresses relacionados - tanto para estudantes como para as sociedades em geral - é mais importante do que sempre. Pesquisas também mostram que o SEL contribui para um melhor comportamento na sala de aula. Crianças com habilidades sociais e emocionais mais desenvolvidas são mais empáticas e cooperativas com seus pares, 0 que significa que 0 desenvolvimento do SEL pode impactar positivamente significativamente o bullying nas escolas, bem como a forma de encarar e resolver conflitos. O SEL também pode ajudar a melhorar as habilidades cognitivas, como a memória, levando a um maior sucesso acadêmico durante a escolaridade, desde pré-K até a escola de pós-graduação. (SALZBURG GLOBAL SEMINAR, 2016, p. 8) (grifo nosso)

No Brasil, as competências sociais e emocionais foram abordadas dentro da terminologia das Competências Gerais da BNCC, que traz como um dos seus objetivos o desenvolvimento de 10 (dez) competências que buscam assegurar "uma formação humana integral que visa à construção de uma sociedade justa, democrática e inclusiva" (BRASIL, 2018, p. 25). São elas:

1. Valorizar e utilizar os conhecimentos historicamente construídos sobre o mundo físico, social, cultural e digital para entender e explicar a realidade, continuar aprendendo e colaborar para a construção de uma sociedade justa, democrática e inclusiva.

2. Exercitar a curiosidade intelectual e recorrer à abordagem própria das ciências, incluindo a investigação, a reflexão, a análise crítica, a imaginação e a criatividade, para investigar causas, elaborar e testar hipóteses, formular e resolver problemas e criar soluções (inclusive tecnológicas) com base nos conhecimentos das diferentes áreas.

3. Valorizar e fruir as diversas manifestações artísticas e culturais, das locais às mundiais, e também participar de práticas diversificadas da produção artísticocultural.

4. Utilizar diferentes linguagens - verbal (oral ou visual-motora, como Libras, e escrita), corporal, visual, sonora e digital -, bem como conhecimentos das linguagens artística, matemática e científica, para se expressar e partilhar informações, experiências, ideias e sentimentos em diferentes contextos e produzir sentidos que levem ao entendimento mútuo.

5. Compreender, utilizar e criar tecnologias digitais de informação e comunicação de forma crítica, significativa, reflexiva e ética nas diversas práticas sociais (incluindo as escolares) para se comunicar, acessar e disseminar informações, produzir conhecimentos, resolver problemas e exercer protagonismo e autoria na vida pessoal e coletiva.

6. Valorizar a diversidade de saberes e vivências culturais e apropriar-se de conhecimentos e experiências que the possibilitem entender as relações próprias do mundo do trabalho e fazer escolhas alinhadas ao exercício da cidadania e ao seu projeto de vida, com liberdade, autonomia, consciência crítica e responsabilidade.

7. Argumentar com base em fatos, dados e informações confiáveis, para formular, negociar e defender ideias, pontos de vista e decisões comuns que respeitem e promovam os direitos humanos, a consciência socioambiental e o consumo responsável em âmbito local, regional e global, com posicionamento ético em relação ao cuidado de si mesmo, dos outros e do planeta.

8. Conhecer-se, apreciar-se e cuidar de sua saúde física e emocional, compreendendo-se na diversidade humana e reconhecendo suas emoções e as dos outros, com autocrítica e capacidade para lidar com elas.

9. Exercitar a empatia, o diálogo, a resolução de conflitos e a cooperação, fazendo-se respeitar e promovendo o respeito ao outro e aos direitos humanos, 
com acolhimento e valorização da diversidade de indivíduos e de grupos sociais, seus saberes, identidades, culturas e potencialidades, sem preconceitos de qualquer natureza.

10. Agir pessoal e coletivamente com autonomia, responsabilidade, flexibilidade, resiliência e determinação, tomando decisões com base em princípios éticos, democráticos, inclusivos, sustentáveis e solidários. (BRASIL, 2018, p. 9-10) (grifo nosso)

Como podemos notar, as competências gerais da BNCC apontam também para uma educação que promova uma consciência socioambiental e responsável que está preocupada com o cuidado que as crianças devem ter consigo, com o outro e com o planeta. Ao se sentirem pertencentes de uma mesma comunidade social e ambiental, o respeito e a responsabilidade para com os outros grupos diversos e o planeta tornam-se tão importantes quanto o cuidado consigo.

Por isso, as competências gerais da BNCC devem apenas servir como diretrizes orientadoras à estados e municípios que, com suas autonomias, deverão incorporá-las nos projetos pedagógicos de suas redes de ensino. Essas competências são úteis para demonstrar, junto com outros documentos já apresentados, que, tanto uma educação em direitos humanos como também uma educação socioambiental, são imprescindíveis para a formação de cidadãs/aos mais conscientes com os desafios sociais e ambientais que no Brasil se apresentam todos os dias e deixam tantas vítimas e danos irreparáveis.

\section{BNCC E ÉTICA AMBIENTAL: pontes de diálogo para a educação ambiental}

A Política Nacional de Educação Ambiental, estabelecida por meio da Lei nº 9.795/99, afirma que essa educação deve ser integralizada de maneira global e articulada, isto é, deve estar presente "em todos os níveis e modalidades do processo educativo, em caráter formal e não-formal" (art. $2^{\circ}$ ).

Em termos de definição, o artigo $1^{\circ}$ da referida Lei dispõe que:

Art. $1^{\circ}$ Entendem-se por educação ambiental os processos por meio dos quais o indivíduo e a coletividade constroem valores sociais, conhecimentos, habilidades, atitudes e competências voltadas para a conservação do meio ambiente, bem de uso comum do povo, essencial à sadia qualidade de vida e sua sustentabilidade. (BRASIL, 1999) (grifo nosso)

Percebe-se que este conceito esta alinhado com o artigo 225 da Constituição Federal, que trata inclusive da educação ambiental:

Art. 225. Todos têm direito ao meio ambiente ecologicamente equilibrado, bem de uso comum do povo e essencial à sadia qualidade de vida, impondo-se ao Poder Público e à coletividade o dever de defendê-lo e preservá-lo para as presentes e futuras gerações.

$\S 1^{\circ}$ Para assegurar a efetividade desse direito, incumbe ao Poder Público:

[...] $\mathrm{VI}$ - promover a educação ambiental em todos os níveis de ensino e a conscientização pública para a preservação do meio ambiente; [...] (BRASIL, 1988) (grifo nosso)

A BNCC, por sua vez, incumbe aos sistemas, às redes de ensino e às escolas, incluir também, de forma transversal e integradora, a educação ambiental disposta na Política Nacional de Educação Ambiental (Lei n 9.795/1999) e nas Diretrizes Curriculares Nacionais para a Educação Ambiental (Parecer CNE/CP n 14/2012 e Resolução CNE/CP n 2/201218). "Na BNCC, essas temáticas são contempladas em habilidades dos componentes curriculares, cabendo aos sistemas de ensino e escolas, de acordo com suas especificidades, tratá-las de forma contextualizada." (BRASIL, 2018, p. 20). 
A partir desse marco legal e teórico estabelecido na política educacional brasileira, deparamo-nos com o desafio de compreender como essas competências que demandam um "posicionamento ético em relação ao cuidado de si mesmo, dos outros e do planeta", conforme estabelece a Competência Geral $n^{\circ}$ 7 da BNCC, dialogam com uma ética genuinamente ambiental. Isto é, o que significa cuidar do planeta? Como se faz isso?

Essas são questões complexas que dizem respeito as ações do sujeito e entram também no campo da moralidade e da ética aplicada. Que tipo de pertencimento pode existir entre os sujeitos e a natureza? Quais são os valores e quais são as responsabilidades que demandam dela? Importante lembrar que quando fazemos essas perguntas estamos nos reportando às habilidades socioemocionais (soft skills).

Por fim, qual é o aprendizado social e emocional (SEL) que se busca, ou seja, quais são as atitudes e as habilidades necessárias para garantir a sustentabilidade ambiental? Como dito, é preciso buscar no campo da ética os princípios morais que orientam as condutas dos indivíduos em relação à natureza. Portanto, a ética ambiental deve ser compreendida nesse contexto como um elemento fundamental, na medida em que a consideração moral da natureza é necessária para estabelecer relações sustentáveis, inclusivas e solidárias e, consequentemente, garantir a justiça socioambiental vislumbrada tanto pela educação ambiental quanto pela EDH e pela ECG, de maneira mais abrangente.

Nesse sentido, é importante compreender que a própria Constituição Federal, e a Política Nacional de Educação Ambiental dela decorrente, embora seja considerada uma legislação avançada em termos da defesa do meio ambiente, ainda o faz por meio de valores instrumentais: o meio ambiente é um "bem" de uso comum do povo. Além disso, também é antropocêntrico, na medida em que sua preservação deve ser feita para "as presentes e futuras gerações" da humanidade.

Essa visão constitucional reflete a tradição jucaido-greco-romano-cristã, que hierarquiza os seres vivos a partir do critério da racionalidade. Os seres dotados de razão, pensamento, linguagem e consciência, além do poder de agir em defesa dos seus interesses e contrariamente ao interesse de quaisquer outros seres, isto é, os seres humanos, têm um estatuto moral superior aos demais seres vivos (FELIPE, 2003, p. 19).

Desse pensamento decorrem práticas discriminatórias semelhante ao machismo, ao racismo e outros "ismos" de dominação: o naturismo e o especismo. Karen J. Warren (2000), filósofa ecofeminista e professora da Macalester College, explica que o naturismo é o termo utilizado para se referir à dominação injustificada da natureza. Ou seja, é o termo utilizado pela autora para conceituar a forma de discriminação dos não humanos, chamados por ela de "Outros terrestres", evidenciado nessa linguagem a ausência do antropocentrismo que hierarquiza as diferentes formas de vida que habitam a Terra.

A filósofa Sônia T. Felipe, Doutora em Teoria Política e Filosofia Prática pela Universidade de Konstanz (Alemanha) e Pós-doutora em Bioética-Ética Animal pela Universidade de Lisboa, assim conceitua o especismo:

Discriminação de animais não-humanos, praticada pelos seres humanos, rebaixando o estatuto daqueles, em função de não terem nascido na espécie humana e de terem características diferentes em sua configuração biológica, ainda que sejam sujeitos de experiências similares às dos seres humanos, por exemplo, dor e sofrimento". (FELIPE, 2006, p. 210)

A Política Nacional de Educação Ambiental estabelece, no artigo $4^{\circ}$, quais são os seus princípios básicos ${ }^{4}$. Dentre eles, orienta que o meio ambiente deve ser compreendido em sua totalidade, isto é,

\footnotetext{
4 “Art. 4ํo São princípios básicos da educação ambiental:

I - o enfoque humanista, holístico, democrático e participativo;

II - a concepção do meio ambiente em sua totalidade, considerando a interdependência entre o meio natural, o sócio-econômico e o cultural, sob o enfoque da sustentabilidade;

III - o pluralismo de idéias e concepções pedagógicas, na perspectiva da inter, multi e transdisciplinaridade;

IV - a vinculação entre a ética, a educação, o trabalho e as práticas sociais;

$\mathrm{V}$ - a garantia de continuidade e permanência do processo educativo;

VI - a permanente avaliação crítica do processo educativo;
} 
reconhecendo a interdependência socioambiental para a sustentabilidade. Contudo, por se tratar de legislação infraconstitucional, ela deve ser interpretada à luz do artigo 225 da Constituição Federal. Este, como visto anteriormente, dispõe sobre o direito de todos ao meio ambiente ecologicamente equilibrado.

Ao garanti-lo, a Constituição estabelece um direito vinculado a este bem: de uso comum do povo e essencial à sadia qualidade de vida. Contudo, esse bem se encontra em uma nova categoria criada na Constituição, o bem difuso. Assim, por não ser bem público nem privado, algumas características atinentes a estes dois últimos (direito de usar, fruir, gozar e dispor do bem) são destacadas do bem difuso (FIORILLO, 2004).

Entretanto, esse bem de uso comum do povo só é passível de ser caracterizado como bem ambiental, e porquanto difuso, se essencial à sadia qualidade de vida dos seres humanos, que são os destinatários da norma constitucional. O princípio fundamental estabelecido na Constituição é o da dignidade da pessoa humana, no qual toda a norma constitucional se fundamenta, inclusive a tutela ambiental. Apesar de ser inovadora nesse aspecto - preocupação com as atuais e futuras gerações - a Constituição visa tutelar o direito à vida humana por meio da preservação do seu patrimônio genético (FIORILLO, 2004).

No limite, a doutrina jurídica tradicional entende que o viés antropocêntrico é necessário à preservação ambiental, visto que, nas palavras de Fiorillo (2004, p. 15-16), “[...] o único animal racional é o homem, cabendo a este a preservação das espécies, incluindo a sua própria". Apesar de não ser possível generalizar esse pensamento e afirmar que toda doutrina ambiental tenha esse posicionamento, tampouco seria possível afirmar que a legislação ambiental, inclusive sobre educação, não reflete esse viés antropocêntrico do qual decorrem naturismo e especismo.

Exemplo disso é fo próprio undamento para a proteção da fauna: ela possui uma função ecológica pela qual a manutenção do equilíbrio dos ecossistemas é viabilizada, tornando-se indispensável à sadia qualidade de vida humana. É objeto de proteção, com natureza jurídica de bem ambiental, logo de uso comum do povo (FIORILLO, 2004). Enquanto bem difuso, deixa de ser tratado pelo regime privado de propriedade, conforme a visão tradicional do Direito 5 . A finalidade da fauna se dá com relação à utilidade que esta apresenta aos seres humanos e à manutenção do equilíbrio ecológico. Resta evidente, portanto, o viés naturista e especista da alegada proteção, por meio de um valor meramente instrumental.

Embora naturismo e especismo estejam amplamente arraigados em muitas culturas, ambos não deixam de ser refletidos e, inclusive, contestados à luz de outros critérios de considerabilidade moral que não a razão (o critério antropocêntrico). Para Peter Singer, por exemplo, esse critério é o da "igual consideração de interesses semelhantes. Para Tom Regan, por sua vez, é o fato de cada animal, seja humano ou não humano, ser sujeito de sua vida.

Ao colocar a vida, a vulnerabilidade ou a capacidade de sentir dor ou prazer, por exemplo, como critério para definir quem é merecedor - ou não - de consideração moral e, consequentemente, de ter sua vida, integridade física e psicológica preservadas, a ampliação do círculo de moralidade para além dos humanos se torna necessária.

Nesse sentido, o posicionamento antiespecista questiona a coerência moral dos direitos postulados e vigentes nas nações humanas, pois a alegação de alto grau de refinamento racional autointitulado demanda a responsabilidade nos seus princípios éticos fomentados nos últimos séculos pelos demais movimentos abolicionista-libertários.

A empatia e o cuidado, como habilidades e competências trabalhadas por meio da educação em direitos humanos, têm o potencial de despertar essa consciência crítica em relação ao meio no qual

VII - a abordagem articulada das questões ambientais locais, regionais, nacionais e globais;

VIII - o reconhecimento e o respeito à pluralidade e à diversidade individual e cultural." (BRASIL, 1999).

${ }^{5}$ Ressalta-se que nessa concepção de fauna não se encontram os animais domésticos e/ou domesticados, que têm outro status jurídico (coisas), regulamentando pelo Código Civil. 
estamos inseridos e perceber as relações de opressão que existem não só em relação aos humanos como o machismo, o racismo, o classismo e assim por diante - mas também em relação à natureza e aos animais. Nesse sentido,

as ecofeministas mostram que os argumentos racionais, ou uma ética baseada em princípios, não são suficientes para o fim da exploração, justamente porque diferentes sistemas de exploração estão imbricados e somente a partir do reconhecimento dessa relação é possível combatê-los. Isso, por sua vez, só é possível quando valores como o cuidado e a empatia, por exemplo, forem moralmente considerados. (ROSENDO, 2015, p. 192).

Desse modo, ao compreender que diferentes formas de discriminação estão logicamente interconectadas ${ }^{6}$, é preciso repensar todas as práticas que de algum modo hierarquizem e inferiorizem alguns grupos em detrimentos de outros, como o fazem o machismo, o racismo, o classismo e o especismo, por exemplo.

\section{CONSIDERAÇÕES FINAIS}

Os desafios que a educação apresentam no Brasil são diversos, que vão desde o acesso e permanência até a formação de valores e sujeitos comprometidos com respeito, igualdade e cidadania. A Educação em Direitos Humanos e a Educação para a Cidadania Global, que incluem também elementos da Educação Ambiental, são fundamentais nessa visão democrática e inclusiva.

Dessa forma, pensar uma educação que inclui o desenvolvimento não só de competências cognitivas, mas também socioemocionais, é um requisito para a construção dessa sociedade almejada: justa, igualitária e sustentável. Tendo em vista essa preocupação, a Base Nacional Comum Curricular estabelece as 10 (dez) competências gerais que devem ser desenvolvidas por todos/as os/as educandos/as.

Contudo, é preciso um referencial a partir do qual se defina como deve ser essa educação ambiental, especialmente quando se trata do quesito sustentabilidade. Estabelecida a ponte de diálogo entre a BNCC e a educação ambiental, quais são os princípios que devem nortear essa prática? O que significa ter empatia com esse outro que é a natureza, nela incluídos os animais?

Ao buscar responder essas questões, vimos que a Política Nacional de Educação Ambiental ainda é marcada por um viés bastante antropocêntrico, na medida em que atribui ao "meio ambiente" um valor instrumental. Ou seja, sua preservação é feita com base no interesse das presentes e futuras gerações humanas.

Outros critérios de consideração moral demonstram que é possível estabelecer outras formas de relação com animais e natureza, que considerem os interesses a partir de uma visão não antropocêntrica, ou seja, que não hierarquize diferentes formas de vida.

Quando se percebe que há uma lógica de dominação que permeia diferentes "ismos" de dominação - machismo, classismo, racismo, especismo e assim por diante - é necessário se comprometer também com valores e práticas que não incorram nessas práticas discriminatórias.

Nesse sentido, a BNCC e a educação ambiental são instrumentos ricos para desenvolver essas habilidades socioemocionais que permitem aos indivíduos praticar a empatia e o cuidado - de si e do outro, seja um outro humano ou não humano. Entretanto, é fundamental que essa educação seja de fato inclusiva e orientada por uma ética genuinamente ambiental, sob pena de mantermos privilégios e opressões que marcam discursos rasos e antropocêntricos de sustentabilidade ambiental.

\section{REFERÊNCIAS}

BRASIL. Comitê Nacional de Educação em Direitos Humanos. Plano Nacional de Educação em Direitos Humanos. Brasília: Secretaria Especial dos Direitos Humanos, Ministério da Educação, Ministério da Justiça, UNESCO, 2007. Disponível em:

\footnotetext{
${ }^{6}$ Para compreender as estruturas conceituais opressoras e a lógica da dominação, cf. ROSENDO, Daniela. Sensível ao Cuidado: Uma perspectiva ética ecofeminista. Curitiba: Prismas, 2015.
} 
<http://portal.mec.gov.br/index.php?option=com_docman\&view=download\&alias=2191-plano-nacionalpdf\&category_slug=dezembro-2009-pdf\&Itemid=30192 >. Acesso em: 8 mar. 2018.

. Constituição (1988). Constituição da República Federativa do Brasil de 1988. Disponível em:

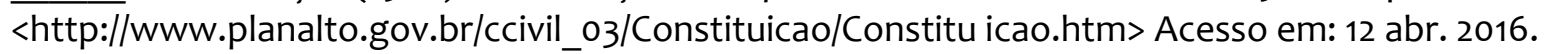

. Lei $n^{\circ} 9.795$, de 27 de abril de 1999. Dispõe sobre a educação ambiental, institui a Política Nacional de Educação Ambiental e dá outras providências. Diário Oficial da União, Brasília, 28 de abril de 1999. Disponível em: <http://www.planalto.gov.br/ccivil_03/leis/L9795.htm>. Acesso em: 1 jun. 2018.

. Lei $n^{\circ} 13.005$, de 25 de junho de 2014. Aprova o Plano Nacional de Educação - PNE e dá outras providências. Disponível em: <http://www.planalto.gov.br/ccivil_03/_ato2011-2014/2014/lei//13005.htm>. Acesso em: 14 jan. 2018.

. Ministério da Educação. Base Nacional Comum Curricular. Brasília: MEC, 2018.

. Secretaria de Direitos Humanos da Presidência da República. Educação em Direitos Humanos: Diretrizes Nacionais. Brasília: Coordenação Geral de Educação em SDH/PR, Direitos Humanos, Secretaria Nacional de Promoção e Defesa dos Direitos Humanos, 2013.

CASARIN, Tônia. O que você precisa saber sobre Inteligência Emocional e Social? 2016 Disponível em: <https://www.toniacasarin.com.br/o-que-voce-precisa-saber-sobre-inteligencia-emocional-e-social/>. Acesso em: 8 mar. 2018.

DELORS, Jacques. Educação: um tesouro a descobrir. Relatório para a UNESCO da Comissão Internacional sobre Educação para o século XXI. UNESCO: Brasília, 2010. Disponível em: <http://unesdoc.unesco.org/images/0010/001095/10959opor.pdf>. Acesso em: 15 jan. 2018.

FELIPE, Sônia T. Fundamentação ética dos direitos animais: O legado de Humphry Primatt. In: SANTANA, Heron José de; SANTANA, Luciano Rocha (Coord). Revista Brasileira de Direito Animal. Salvador: Instituto de Abolicionismo Animal, ano 1, n 1, jan-dez 2006.

. Por uma questão de princípios: alcance a limites da ética de Peter Singer em defesa dos animais. Florianópolis: Boiteux, 2003.

FIORILLO, Celso Antonio Pacheco. Curso de Direito Ambiental Brasileiro. 5. ed. São Paulo: Saraiva, 2004.

GAMA, Zacarias. A elite do atraso. Disponível em: <http://justificando.cartacapital.com.br/2 018/01/16/elitedo-atraso-e-base-nacional-curricular-comum-bncc|\#_ftn1>. Acesso em: jul. 2018.

LAPA, Fernanda Brandão. Clínica de Direitos Humanos: uma proposta metodológica para a educação jurídica no Brasil. Rio de Janeiro: Lúmen Juris, 2014.

LAPA, Fernanda Brandão; RODRIGUES, Horácio Wanderlei. Educação em Direitos Humanos: marcos legais e (in)efetividades. Revista Direitos Sociais e Políticas Públicas - UNIFAFIBE, vol. 4, p. 181-226, 2016.

LEMANN CENTER. Base Nacional Comum Curricular. Parte I: Implementação da BNC: Lições do "Common Core”. Por David Plank, 2016.

ONU. Resolução 49/184. Década das Nações Unidas para a Educação em matéria de Direitos Humanos 1995-2004. ONU: 1994.

. Resolución 66/137 aprobada por la Asamblea General el 19 de diciembre de 2011, "Declaración de las Naciones Unidas sobre Educación em Materia de Derechos Humanos". ONU: 2011.

NUNES, Flaviana Gasparotti. Professores e parâmetros curriculares nacionais (PCN): como está essa relação?, p. 95-96.

REIMERS, Fernando. Educating for Global Competency. 2009a 
, Fernando. It's Time to Teach Human Rights. In: Harvard Ed. Magazine, Winter 2009b. Disponível em: <https://www.gse.harvard.edu/news/ed/09/01/its-time-teach-human-rights >. Acesso em: 15 mar. 2018.

ROSENDO, Daniela. Sensível ao Cuidado: Uma perspectiva ética ecofeminista. Curitiba: Prismas, 2015. SALZBURG GLOBAL SEMINAR. Session 566, Salzburg, December 4 to 9. Getting Smart: Measuring and Evaluating Social and Emotional Skills, 2016.

UNESCO. Educação para a cidadania global: a abordagem da UNESCO. Brasília: ONU: $2015 a$. . Educação para a cidadania global: preparando alunos para os desafios do século XXI. Brasília: UNESCO, 2015b.

XIMENES, Salomão; CÁSSIO, Fernando. Uma base em falso. Disponível em: <https://www.nexojornal.com.br/ensaio/2017/Uma-Base-em-falso>. Acesso em: jul. 2018.

WARREN, Karen. Ecofeminist Philosophy: A Western Perspective on What It is and Why It Matters. Rowman \& Littlefield Publishers, 2000. 